\title{
Effect of homeopathy on chronic tension-type headache: a pragmatic, randomised controlled single blind trial
}

\author{
N Sharma ${ }^{1}$, A Ameta ${ }^{1 *}$, S Sharma ${ }^{2}$ \\ From The European Headache and Migraine Trust International Congress \\ London, UK. 20-23 September 2012
}

\section{Introduction}

Homeopathy is increasingly used by headache patients in general practice but scientific evidence is lacking. We therefore designed a clinical trial in a way that would not change the practice pattern of homeopathic physicians.

\section{Purpose/ background/ objectives}

The purpose of the study was to explore individualised homeopathic treatment used in general practice for chronic tension type headache (CCTH).

\section{Methods}

The study was multicentre, pragmatic, randomised controlled trail with blinded assessment. One hundred twenty seven participants with CTTH were randomly assigned to homeopathy or to usual care. Number of headache attacks, duration of pain, pain intensity on visual analog scale, use of medication and resources were recorded through headache diary at 4 weeks run-in-period (baseline), at week 17 post interventions, and end of follow up at week 29. An observer blind to the patients' treatment allocation carried out assessments.

\section{Results}

headache frequency and intensity was lower in the homeopathy group than in controls after intervention $(\mathrm{p}<0.05)$ and at follow up $(\mathrm{p}<0.001)$. The pain duration was shortened slightly after the intervention period reached to significance level at follow up. In homeopathy group headache parameters decreased at post intervention compared with baseline and continued to decrease slightly in follow up period. The overall evaluation of the
2 treatments indicated improvements in both the treatment but later only homeopathy group showed consistent change. Compared with usual care, patients randomised to homeopathy used $35 \%$ less medication $(P=0.001)$ and had $45 \%$ fewer visits to general practitioners $(\mathrm{P}=0.0001)$.

\section{Conclusion}

The results indicate that homeopathy could have clinically relevant benefits for patients with chronic tension type headache.

\section{Author details}

${ }^{1}$ NMP Medical Research Institute, India. ${ }^{2}$ Medical Directorate, Govt. of Rajasthan, India.

Published: 21 February 2013

\section{References}

1. Ernst E: Homeopathic prophylaxis of headaches and migraine? A systematic review. J Pain Symptom Manage 1999, 18:353-357.

2. Walach $\mathrm{H}$, Lowes, Mussbach : The long-term effects of homeopathic treatment of chronic headaches: 1 year follow up. Cephalalgia 2000, 20:835-837.

doi:10.1186/1129-2377-14-S1-P56

Cite this article as: Sharma et al:: Effect of homeopathy on chronic tension-type headache: a pragmatic, randomised controlled single blind trial. The Journal of Headache and Pain 2013 14(Suppl 1):P56. 